\title{
A prática gerencial do enfermeiro no PSF na perspectiva da sua ação pedagógica educativa: uma breve reflexão
}

\author{
The managerial practice of the nurse within the FH P (Family \\ Health Program) from the perspective of his/her educational \\ and pedagogical action: a brief reflection
}

Lygia M aria deFigueiredo M elo Villas Bôas ${ }^{1}$

M arize Barros deSouza Araújo ${ }^{2}$

Rosalba Pessoa de Souza Timóteo ${ }^{3}$

\footnotetext{
${ }^{1}$ Escola deEnfermagem de Natal, UFRN . Rua Guarujá 3944, N eópolis. 59080-040 Natal RN.

villasboas@digizap.com.br ${ }^{2}$ Secretaria M unicipal de

Saúdedo $N$ atal.

${ }^{3}$ Departamento de

Enfermagem, UFRN.
}

Abstract This article deals with the educational and managerial actions of nurses in the Family Health Program (FH P). It traces the reality of the FHP within the institutional setting of the city of $\mathrm{N}$ atal/RN, raises some questions and analyzes the educational action of the program in the daily routine of the Health Units in the light of the literature. Its objective is to contribute to the reflection about the managerial action of the nurse in that setting, in connection with pedagogical and educational action. The study demonstrates that, as a result of its innovative nature, the Family $\mathrm{H}$ eal th Strategy is facing challenges such as the need to define the profile of competencies for these professionals, their qualification processes, continued and permanent education, and new managerial models for nursing that should specifically meet the daily demands.

Key words Nursing management, Health work process, Family health education
Resumo 0 presente artigo trata da prática educativa gerencial do enfermeiro no Programa Saúdeda Família (PSF). Resgata a realidadedestePrograma no cenário institucional de $\mathrm{N}$ atal/RN , suscita alguns questionamentos e faz uma análise da sua ação educativa no espaço cotidiano das U nidades de Saúde da Família (U SF), à luz da literatura. Objetiva contribuir com a reflexão acerca do fazer gerencial do enfermeiro nesse cenário, articulando-o à ação pedagógica/educacional. Como resultados, identifica que o caráter inovador da Estratégia Saúde da Família (ESF) evidencia desafios que se relacionam à necessidade de se definir as competências necessárias aos profissionais, aos seus processos de formação, educação continuada e permanente e aos novos modelos gerenciais para a enfermagem, que atendam, especificamente, as demandas desse cotidiano.

Palavras-chave Gerência na enfermagem, Processo de trabalho em saúde, Ação educativa na Saúde da Família 
Introdução

O Programa de Saúde da Família (PSF), implantado no Brasil há mais de uma década, vem se consolidando como uma estratégia de reorientação das práticas assistenciais. No entanto, ainda se observa que a sua implantação e desenvolvimento nos municípios brasileiros têm ocorrido de forma variada, do mesmo modo que a compreensão dessa estratégia, por parte dos diversos atores envolvidos (gestores, profissionais e população).

A cada momento, evidencia-se a necessidade de se intervir no processo de produção de serviços e no trabal ho dos profissionais, redefinindose objetos, métodos e instrumentos, na perspectiva do enfrentamento dos problemas impostos por essa realidade.

Em 1994, Natal adere ao PSF. Entretanto, é só a partir de 1997 que este começa a despertar interesse no cenário da Secretaria M unicipal de Saúde de $\mathrm{N}$ atal (SM S-N atal) ${ }^{1}$.

De acordo com o estudo realizado por Rocha ${ }^{1}$, a implantação do programa se deu em 1998 , nas áreas previamenteselecionadas, com base em critérios epidemiológicos, principalmente por apresentarem maior índice de mortalidade infantil, maior concentração de favelas e isolamento em relação a serviços assistenciais. A sua ampliação ocorre quando o PSF é implantado, em 2002, no Distrito Sanitário Norte da cidade de $\mathrm{N}$ atal, área considerada prioritária, tendo em vista o grande contingente populacional e as carências relativas a bens e serviços públicos de saúde.

D esde então, diversas dificuldades são apresentadas pelas equipes do PSF, sendo consideradas prioritárias as que dizem respeito à estruturação da atenção básica, às debilidades e descontinuidades na implantação de ações intersetoriais e de promoção à saúde, bem como às relativas ao apoio institucional eao perfil dealguns profissionais. Estas dificuldades, cotidianamente sentidas pelas equipes, são identificadas pelas enfermeiras como elementos redutores de autonomia, interferindo no processo de trabalho das mesmas ${ }^{2,3}$.

Sabe-seque, nas Unidades de Saúde da Família (USF), os enfermeiros desenvolvem, no diaa-dia, múltiplas atividades no campo da assistência, da gerência e da educação/formação, ampliando as suas responsabilidades, que associadas às dificuldades existentes e ao interesse em proporcionar o bom andamento do serviço, sobrecarregam o seu cotidiano, tornando o processo de trabalho algo estressante.

Em N atal, nos últimos anos, tem-se desen- volvido parcerias entre as instituições formadoras e os serviços, o que acarreta, para os enfermeiros das USF, assumir atividades ligadas à supervisão de estagiários, preceptoria/tutoria de disciplina multiprofissional, participação em projetos de extensão e pesquisa, além de outras atribuições ligadas ao processo deaprendizagem dos alunos da área da saúde. As inúmeras ações assumidas por esses profissionais, o papel de mediador no processo de trabalho, entre os diversos membros da equipe de saúde da família, o sentimento de tarefismo acentuado, além de serem atribuídos a eles o sucesso ou fracasso dessas ações, têm comprometido diretamente o gerenciamento do processo de trabalho de enfermagem nas USF.

Ainda queo espaço do PSF esteja contribuindo para a construção da autonomia do enfermeiro, pela incorporação de novas competências e tecnologias, além da maior interação ehorizontalização das relações profissionais einterinstitucionais, não se observa que esse fato favoreça a melhoria da qualidade da ação pedagógica no fazer gerencial do enfermeiro ${ }^{2,3}$.

Tal realidade produz inquietações acerca do papel social dos sujeitos que realizam uma prática pedagógica no campo do trabal ho, de modo a potencializar esteespaço, no desenvolvimento de uma ação transformadora. N este sentido, cabe o questionamento: como tornar o fazer gerencial do enfermeiro nas USF uma prática pedagógica transformadora que leva à emancipação e à autonomia dos sujeitos envolvidos?

0 grande desafio para os trabalhadores do PSF, em especial os da enfermagem, é a necessidade de rever sua prática diante de novos paradigmas, sendo indispensável repensar os processos de trabalho, bem como adotar metodologias, instrumentos e conhecimentos diferentes dos atualmente instituídos.

No PSF, a enfermagem constitui uma parcela do trabalho que também se encontra presentena produção de serviços de saúde no nível coletivo. Inserida nesse contexto, precisa ser capaz de identificar as necessidades sociais de saúde da população sob a sua responsabilidade, além de intervir no processo saúde/doença dos indivíduos, família e coletividade 4 . 0 trabalho do enfermeiro, dessemodo, se dá numa relação deinterdependência com outros trabalhos na saúde, sendo esse agir conseqüência da produção de um conjunto de procedimentos (atos de saúde), os quais, em grande parte, estão sob sua responsabilidade ${ }^{5}$.

A educação e a saúde, enquanto práticas sociais perpassadas por várias racionalidades, de- 
vem ser compreendidas como constituintes de uma sociedade concreta, as quais sofrem sua interferência. Enquanto práticas que emanam das relações sociais que as envolvem, podem potencializar a compreensão do homem construtor de si mesmo edesua própria história, pela descobertae transformação do seu modo de agir6,7. A sua capacidade emancipatória detém o poder de mudar a estrutura social, exigindo de quem educa a clareza sobre a "missão", os compromissos e os acordos estabelecidos, de modo que essa práxis esteja pautada na ação crítica/reflexiva para o alcance do projeto gerencial e educacional proposto ${ }^{8}$.

Partindo desse entendimento, o enfermeiro deve desenvolver competências, mobilizando conhecimentos, habilidades eatitudes, em situações concretas de trabalho, que o levem a articular a prática pedagógica de caráter emancipatório e transformador à gerência orientada pela visão crítica e global da sociedade, na perspectiva do cuidado integral e de qualidade 9 .

Desse modo, refletir sobre a construção e 0 redimensionamento dos processos pedagógicos nas USF torna-se urgente, mesmo que não se tenha clareza de todas as etapas a serem trilhadas. 0 fato de não se definir a priori os passos não significa necessariamente caminhar no escuro; ao contrário, é importante produzir dados que, ordenados, interpretados e sentidos coletivamente, servirão de instrumentos reorientadores para novas práticas ${ }^{10}$.

Este artigo tem, pois, como objetivo contribuir com a reflexão acerca do fazer gerencial do enfermeiro no PSF, articulando a ação pedagógica/educacional.

\section{Refletindo}

sobre a prática educativa gerencial no PSF

A gerência de enfermagem está articulada a um processo maior, que é o gerenciamento em saúde. No caso do PSF, é fato a ampliação da complexidade das atividades que são desenvolvidas pelas equipes. Isto requer, de todos os profissionais, a apropriação de novos conhecimentos, habilidades e tecnologias que venham a possibilitar a organização dos serviços, na perspectiva da garantia do acesso e integralidade da atenção. No entanto, transformar o agir gerencial do enfermeiro em uma prática educativa que leva os indivíduos à auto-avaliação e mudança da sua ação em algo criativo, democrático e cidadão é um grande desafio.

Convém ressaltar que tal desafio recai na ne cessidade de construção e desenvolvimento, de forma articulada, das competências de natureza técnica, organizacional, comunicativa e sociopolítica. 0 profissional deve ter clareza de que essa construção extrapola um corpo de conhecimentos, na medida em que a responsabilidade ea atitude social devem ocorrer simultaneamente. Isso significa dizer que a atuação do profissional enfermeiro "se expressa na competência humana para o cuidar, em suas múltiplas dimensões teórico-científica, social, política e, sobretudo, ética"

É também, de forma multidimensional, que deve ser compreendida a função do enfermeiro. Torna-se urgente a necessidade de redimensioná-la para atender aos novos arranjos e desenhos, nos diferentes processos de trabal hos existentes no Sistema Ú nico de Saúde (SUS). Uma vez quea função gerencial da enfermagem constitui uma prática de relações determinada historicamente, é necessário contextualizá-la, e compreendê-la, como função que se institucionaliza com a própria enfermagem. Assim, 0 agir gerencial vem ao longo dos anos reproduzindo padrões normativos, verticalizadores, centralizadores e acríticos ${ }^{11,12}$.

Do mesmo modo, no espaço cotidiano, as enfermeiras se deparam com normas e regras estabelecidas, e, muitas vezes, seenvolvem no diaa-dia das atividades técnicas e burocráticas muito centradas em parâmetros quantitativos. Ao assumir o processo de trabal ho assistencial, a enfermeira toma como objeto as necessidades do cuidar, cuja finalidade se refereà ação integral da enfermagem. No processo gerencial, o seu objeto passa a ser os trabal hadores da enfermagem e a organização do trabalho, tendo por finalidade a implementação de adequadas condições detrabalho e de cuidado de enfermagem ${ }^{13}$.

No processo educativo, que deve permear toda e qualquer ação da enfermagem, compreende-sequeo seu objeto são os sujeitos da aprendizagem inseridos na prática pedagógica, a qual deverá articular os referenciais teórico-práticose histórico-sociais da educação em geral, da educação profissional e da ação em saúde, na vivência de processos pedagógicos formativos. Tais processos, por sua vez, deverão incorporar propostas emancipadoras coerentes com a competência humana para o cuidar?.

No caso do PSF, a responsabilidade dos processos de supervisão eformação amplia-se quando, além da equipe de enfermagem, encontramse inseridos os Agentes Comunitários de Saúde (ACS).

Em relação aos ACS, o processo de supervi- 
são ainda se encontra permeado por mecanismos de controle, principalmente quando se acha relacionado à concepção de supervisão de cada enfermeiro. Da mesma forma, os processos de qualificação são marcados pela fragmentação, desestruturação, que, na maioria das vezes, não permitem o desenvolvimento de competências que têm como eixo orientador a integralidade 3 .

No fazer do ACS, existe um conjunto de situações, para o qual a área da saúde ainda não conseguiu desenvolver um saber sistematizado, os instrumentos gerenciais, nem instrumentos de trabalho ${ }^{14}$. Desse modo, afirma-se que na sistematização do saber do ACS, a partir do cotidiano do seu trabalho, é imprescindível que sejam envolvidos os espaços da supervisão e da gerência.

No caso específico da supervisão da equipe deenfermagem, apesar deas características desse processo terem sofrido modificações ao longo dos anos, o que tem levado essa prática a se reconstruir e a se refazer, a cada momento, é o fato de ser considerada como prática histórica e social, determinada de acordo com as relações sociais que ocorrem na sociedade.

Tratando do PSF, no município de Natal, a supervisão de enfermagem está fortemente influenciada pela concepção burocrática e pontual, vinculada à detecção de problemas limitados aos setores de enfermagem, e realizada apenas em momentos específicos da rotina diária. Os momentos de encontro da equipe são comprometidos pelo excesso de atividades curativas, pelo tarefismo e pelo estresse, advindos da pouca organização do processo de trabalho e da alta demanda requerida ao enfermeiro ${ }^{3}$.

Cabe a ressalva de que nem sempre 0 fazer cotidiano pode se constituir em um elemento negativo. 0 problema reside na rotina imposta como fim, sem uma reflexão crítica de sua necessidade em cada contexto, de forma que possibilite 0 avanço no enfrentamento das situações vividas no dia-a-dia dos serviços, contribuindo, assim, para o processo de recriação e renovação de conhecimentos e práticas ${ }^{15}$. Se por um lado, as instituições detêm o monopólio dos objetos edos recursos institucionais, uma vez que são elas quem define o significado objetivo do papel do profissional, por outro, é este profissional que poderomper com o instituído, no momento em que, utilizando-se de sua subjetividade e do seu modo particular de perceber sua ação, elabora a sua situação na instituição, podendo estabelecer sua ordem de relevância que dará, em último caso, sentido ao seu trabalho. Romper com esse quadro significa voltar o olhar para os trabalha- dores em busca de sua maior qualificação, no sentido de lidar com essas questões, o que requer uma política institucional de capacitação e educação permanente e continuada para todos os níveis da rede de serviços.

É possível que, a partir dos núcleos de supervisão, sejam gerados trabalhos de educação continuada, onde supervisores e supervisionados possam discutir as dificuldades e os avanços do processo de prestação de serviços de saúde ${ }^{16}$. A supervisão de enfermagem nesse entendimento teria, a partir de processos educativos, a finalidade de desenvolver o potencial de cada trabalhador, visando qualificar o seu trabalho. Nessa perspectiva, os serviços de saúde constituem espaços privilegiados de mudança; é neste contexto microestrutural que devem ser criadas "linhas de fuga" como estratégia utilizada, onde se buscam possibilidades e se operam situações de mudanças, visando ultrapassar o que está dado ${ }^{17}$.

Campos alerta que para que essas possibilidades se "materializem é necessário reconstruir, destruir, desconstruir, toda uma infinita lógica de micropoderes normalizadores que produzem o conformismo ${ }^{18}$ ". É necessário, pois, partirmos do pressuposto de que a mudança implica a existência de sujeitos capazes de gerirem seu dia-a-dia, explorando ao máximo as potencialidades e respeitando os limites, os constrangimentos e as determinações histórico-estruturais de cada contexto.

Criar linhas de fuga nos processos educativos da enfermagem no PSF significa então gerar estratégias de mudanças nas práticas pedagógicas. Em se tratando do processo de formação e qual ificação de recursos humanos, é indispensável que se tenha definido claramente o perfil do profissional a ser capacitado, as necessidades dessa formação e qualificação, e as competências a serem desenvolvidas nesse processo ${ }^{19}$.

N estecontexto, a enfermeira supervisora/instrutora tem uma parcela de responsabilidade na construção de processos educacionais nos quais sejam utilizadas metodologias facilitadoras e mediadoras da aprendizagem que permitam a criação, a crítica ea reflexão de suas práticas. Isto significa, também, dotar o processo de supervisão de caráter pedagógico, que contemple os diferentes ângulos do trabal ho da equipe de enfermagem, levando-a, conseqüentemente, a uma reflexão contínua do seu fazer.

Encontrar alternativas cotidianas para queas atividades administrativas caminhem integradas às atividades assistenciais, na perspectiva da integralidade, da mudança na formação e da construção do gerenciamento do cuidado voltado 
para uma prática educativa transformadora, constitui um grande desafio. No caso específico da Estratégia de Saúde da Família (ESF), observamos que, no caráter inovador dessa proposta, estes desafios estão postos em diversas ordens, entre eles, a Organização Pan-Americana deSaúde $(\mathrm{OPAS})^{20}$, que identifica a polêmica existente em torno do perfil de competências desses profissionais, conseqüentemente, seus requisitos educacionais e processos de formação correspondentes. Da mesma forma, há questões relacionadas com a qualificação de cada trabalhador, a qual está ligada, por sua vez, à maneira como orientar a sua participação de forma harmônica e complementar.

Recentes estudos apontam ainda para a ne cessidade de as instituições de ensino definirem um projeto político-pedagógico, no qual estejam envolvidos universidades, serviço, comunidade, o que vem sendo fortalecido pela política interministerial que visa a mudança na formação em saúde, em todos os níveis. Esta deve ter como premissa "a formação de profissionais com perfil necessário para 0 atendimento às demandas e às necessidades de saúde da população, abrangendo a saúde nas dimensões biológicas, do estilo de vida, das relações dos seres humanos com o ambiente e os serviços de saúde ${ }^{21 "}$.

Para além da nova conformação do processo de trabalho, devemos ressaltar a importância do Projeto de Profissionalização dos Trabalhadores da Área de Enfermagem (PROFAE), que teve como objetivo a profissionalização intensiva dos trabalhadores de nível médio em enfermagem, bem como a qualificação dos enfermeiros para que possam contribuir com a construção de uma prática mais integral para esses profissionais, na perspectiva de melhoria da qualidade dos serviços de saúde, através da el evação do nível de qualidadee de humanização da assistência prestada ${ }^{22}$. Tais iniciativas abriram espaços para a adoção de uma política de Educação Permanente em Saúde, a qual possibilitou a estruturação dos Pólos de Educação Permanente em todo o país e a implementação dos processos de mudança, representados pela formação de facilitadores e especialistas em ativação de processos de mudança na formação superior de profissionais de saúde.

\section{Considerações finais}

A pesar das dificuldades vivenciadas pel os trabaIhadores da enfermagem, que fazem parte da
SM S de Natal (RN), percebe-se que estas são propulsoras de mudanças que, sem dúvida, contribuirão para o fortalecimento eavanço do SUS no município. Esse avanço pode se dar em maior ou menor intensidade, dependendo da adesão dos profissionais e da instituição a novos processos educativos.

Alguns desses processos, sob a responsabilidade do enfermeiro, deverão ocorrer de modo a favorecer a compreensão da realidade em todas as suas dimensões e que levem à construção de uma prática mais integral, à medida que define um novo papel para esse trabalhador.

$N$ ão é suficiente apenas reconhecer a necessidade de dotar esses processos de um caráter pedagógico. É preciso perceber quea visão fragmentada, existente nos processos educativos, assim como a prática profissional pouco cooperativa, bem como o distanciamento entreas diversas disciplinas, contribuem com a mesma intensidade para tornar a fragmentação um componente bastante presente no cotidiano dos serviços ${ }^{21}$.

0 enfermeiro, responsável direto pela equipe de enfermagem, deve ser capaz de reconhecer, nos processos educativos, um emaranhado derelações e de considerar 0 aprender, o ensinar, o espaço onde este ocorre, os atores envolvidos, como também a finalidade do trabal ho da enfermagem que é o cuidar, numa perspectiva multidimensional.

Portanto, importa em ter que aprender a fazer diferente, ou seja, em re-aprender: estar aberto, acessível e flexível a esse aprendizado que é dinâmico, não linear e muitas vezes contraditório; buscar mais uma vez a ruptura do instituído; romper com a alienação, através da preocupação coletiva com os diversos fazeres, o que leva a reconhecer a necessidade de cooperação e complementaridade dos diversos trabalhos com seus saberes e fazeres específicos. Isto significa caminhar em busca de uma maior horizontalidadedas práticas e responsabilização da equipe de enfermagem, as quais, conseqüentemente, implicarão ganhos ao transformar o cotidiano das práticas em um espaço de produção de autonomias.

O caráter inovador da Estratégia Saúde da Família evidencia uma série de desafios com características diversas. Com certeza, um desses desafios relaciona-se à necessidade de se definir o perfil de competências necessário aos profissionais inseridos no PSF, bem como aos seus processos de formação de educação continuada e permanente.

$\mathrm{N}$ ão existem fórmulas. Existem alternativas de transpor dificuldades, que se tornarão cada vez mais possíveis, quanto mais houver encontros, momentos de troca de saberes e práticas, de 
acolhimento, e, essencialmente, momentos de construção coletiva dessas possibilidades, visando romper com o que está dado.

\section{Colaboradores}

MBS Araújo, LM FM Villas Bôas e RPS Timóteo participaram por igual de todas as etapas de elaboração desse artigo.

\section{Referências}

1. Rocha NSD. Análise do Programa Saúde da Família no município de $\mathrm{N}$ atal-RN : inovações assistenciais? [dissertação]. Rio de Janeiro (RJ): Instituto de Medicina Social, Universidade Estadual do Rio de Janeiro; 2000.

2. Araújo MBS. A Equipe de Saúde no PSF: mudando práticas? Estudo de caso no município de $\mathrm{Natal} / \mathrm{RN}$ [dissertação]. Natal (RN): Programa de Pós-Graduação em Enfermagem, UFRN; 2004.

3. Villas Bôas LM FM. O saber/fazer da Enfermagem no Cotidiano do PSF na Perspectiva de Construção de sua autonomia: um estudo de caso no Distrito Sanitário $\mathrm{N}$ orte de $\mathrm{N}$ atal/RN [dissertação]. Natal (RN): Programa de Pós-Graduação em Enfermagem, UFRN ; 2004.

4. Chiesa AM, Fracolli EA, Sousa M F. Enfermagem, academia e saúde da família. Rev Bras Saúde Fam. 2002; 2(4):52-59.

5. M erhy EE. $O$ ato de governar as tensões constitutivas do agir em saúde como desafio permanente de algumas estratégias gerenciais. Cien Saude Colet 1999; 4(2):305-314.

6. Luckesi CC. Filosofia da educação. São Paulo: Cortez; 1984.

7. Freire P. Educação como prática da liberdade. 27 a ed. Rio de Janeiro: Paz e Terra; 2003.

8. Freire P. Educação e mudança. 27 ạ ed. Rio de Janeiro: Paz e Terra; 2003.

9. Brasil. M inistério da Saúde. Formação Pedagógica em Educação Profissional na Área de Saúde enfermagem. Guia do aluno. Brasília: Ministério da Saúde; 2003.

10. Ferraz CA. Gerenciando o cuidado de enfermagem na unidade de internação. 50 Congresso Brasileiro de Enfermagem; 1998 Out. Salvador: Associação Brasileira de Enfermagem; 1998.

11. Villa TCS, Mishima SM, Rocha SM M. A enfermagem nos serviços de saúde pública do Estado de São Paulo. In: Almeida M CP, Rocha SM M, organizadoras. 0 trabalho de enfermagem. São Paulo: Cortez; 1997. p. 27-60.

12. Formiga JMM. Virando a página: trajetos de uma prática acadêmica em administração [dissertação]. $N$ atal $(R N)$ : Programa de Pós-graduação em Enfermagem, UFRN; 2000.
13. Peduzzi M. O enfermeiro no programa de saúde da família. São Paulo: Secretaria de Estado da Saúde; 2000.

14. Silva JA, Dalmaso ASW. O agente comunitário de saúde e suas atribuições: os desafios para os processos de formação de recursos humanos em saúde. Interface 2002; 6(10):75-83.

15. Baptista MV. A ação profissional no cotidiano. In: $M$ artinelli $M L$, On MLR, Muchail ST, organizadores. 0 uno e o múltiplo nas relações entre as áreas do saber. São Paulo: Cortez; 1998. p. 110-121.

16. M elo MNB. A supervisão em enfermagem. $N$ atal: 2004. [M imeo]

17. M erhy EE. Em busca do tempo perdido: a micropolítica do trabalho vivo em saúde. In: M erhy EE, Onocko R, organizadores. Agir em Saúde: um desafio para o público. São Paulo: Hucitec; 1997. p. 71-112.

18. Campos GWS. Considerações sobre a arte e a ciência da mudança: revolução das coisas e a reforma das pessoas - o caso da saúde. In: Campos GWS, organizador. Inventando a mudança na saúde. São Paulo: Hucitec; 1997. p. 29-87.

19. Tomaz JBC. $O$ agente comunitário de saúde não deve ser um super-herói. Interface 2003; 7(12):74-82.

20. Organização Pan-Americana de Saúde. Organização do cuidado a partir de problemas: uma alternativa metodológica para atuação da equipe de saúde da família. Brasília: OPAS; 2000.

21. Sena RR, Silva KL, Leite JCA, Costa FM. Projeto UNI: cenário de aprender, pensar e construir a interdisciplinaridade na prática pedagógica da enfermagem. Interface 2003; 7(13):79-90.

22. Brasil. Ministério da Saúde. Conselho Nacional de Saúde. 0 desenvolvimento do SUS: avanços, desafios e reafirmação dos seus princípios e diretrizes. Brasília: M inistério da Saúde; 2002.

Artigo apresentado em 14/10/2006

A provado em 19/03//2007

Versão final apresentada em 12/04/2007 